\title{
Teaching Training in Medical Students as an Elective Subject
}

\section{María Esther Urrutia-Aguilar ${ }^{1 *}$, Angélica Arce Cedeño1, Rosalinda Guevara Guzmán¹, Edward Beck ${ }^{2}$, Mónica Beatriz Aburto Arciniega ${ }^{1}$}

\author{
${ }^{1}$ Faculty of Medicine, National Autonomous University of Mexico, Mexico City, Mexico \\ ${ }^{2}$ University of Illinois College of Medicine, Chicago, IL, USA \\ Email: *mariau@unam.mx
}

How to cite this paper: Urrutia-Aguilar, M. E., Cedeño, A. A., Guzmán, R. G., Beck, E., \& Arciniega, M. B. A. (2018). Teaching Training in Medical Students as an Elective Subject. Creative Education, 9, 1212-1220. https://doi.org/10.4236/ce.2018.98090

Received: April 27, 2018

Accepted: June 26, 2018

Published: June 29, 2018

Copyright $\odot 2018$ by authors and Scientific Research Publishing Inc. This work is licensed under the Creative Commons Attribution International License (CC BY 4.0).

http://creativecommons.org/licenses/by/4.0/ (c) (i) Open Access

\begin{abstract}
Background: One of the most significant variables in the learning process is the quality and performance of educators. Therefore, it is necessary to teach future physicians who are considering a career in academia since they often do not have extensive formal training in teaching. The purpose of this study was to evaluate a course developed by the Faculty of Medicine at UNAM that provided medical students with teaching skills. Methods: Eleven (11) students were evaluated at the beginning and two years after successful completion of the course titled Introduction to teaching in the biomedical area. Student acquisition of procedural curricular contents (PCC) was assessed using a pedagogical referent tool that was applied at the beginning and end of the course. Their mastering of behavioral curricular contents (BCC) was evaluated using a rubric focusing on the human qualities of pedagogical leadership and teaching skills. The means of each assessment before and at the completion of the course were compared using T-tests. Results: The results showed that the preference for traditional referents decreased with regards to strategies of "assessment" (36\% to $27 \%)$, "teacher-student relationship" (100\% to $73 \%)$, and "planning" (from $27 \%$ to $9 \%$ ); while the preference for the educational technology referent increased in the "learning" area ( $82 \%$ to $91 \%)$. With regards to assessment of didactic planning, the general performance was high (22 points), standing out "didactic sequence". Out of the dimensions with low performance stand out "teamwork" and "diagnostic assessment". In the assessment of Behavioral Curricular Contents (BCC), a perception with initial high scores in the intrinsic motivation and teaching performance/pedagogical qualities of a leader was identified without finding significant differences after the course ( $p=0.18$ and 0.73 , respectively). Conclusion: The observations in this study demonstrated that medical students had a preference for alternative and educational technology referents at the end of the course that taught them
\end{abstract}


to become academic instructors. The former preference is ideal for the creation of a study plan oriented toward the development of competencies-based courses.

\section{Keywords}

Medical Education, Pedagogical Leadership, Didactic Planning, Academic Medicine

\section{Introduction}

The Commission for Education of Health Professionals in the 21st Century founded in 2009 made recommendations for improvement in medical education, with an emphasis on strengthening the development of professional competences (Bhutta et al., 2010), promoting inter-professional education, and taking advantage of information technology for learning and strengthening educational resources, with particular emphasis on properly training future educators. Research on identifying how to improve educator training has shown that professional training in education begins with our own experiences, first as students and later on as instructors. This is how concepts, beliefs, and theories that strongly influence the way to educate are internalized, and our theories on efficient teaching, learning, and assessment are created (Sanjurjo \& Placci, 2011).

The professional development of instructors is the process in which future educators develop abilities, attitudes and methods resulting in the practical accumulation of his knowledge as well as self-identifying educational values, beliefs, and modalities (Glozer, 1966, quoted by Sanjurjo \& Placci, 2011). In the process of the training to become instructors, factors that influence the early stages of learning theories in educating play an important role in creating qualified educators. This is a particularly critical time, involving intensive learning within regularly unknown contexts, during which, beginners must acquire professional knowledge, in addition to maintaining personal balance (Esquivias et al., 2005). Hence, conceptual and applied knowledge of teaching is essential. Torres et al. (2007) reported that characteristics of an effective college instructor include knowledge of the subject taught and the domains of pedagogy.

However, mastering the domain of contents and of the different pedagogical techniques or strategies only constitute a part of teaching. An essential aspect in the teaching-learning process is that educators-in-training develop the behavioral component of teaching (Pedroza \& Infante, 2010). Given the changes in education paradigm, it is necessary that the future educators perceive the need to develop themselves as pedagogical leaders in terms of becoming a driving factor of improving instruction (Rodríguez-Molina, 2011), as well as become aware of the importance of intrinsic motivation for teaching. Ideally, these traits should be promoted from the beginning of educator training. 
To improve education and training of future medical students, it is necessary that medical students who are interested in becoming future educators be adequately trained through courses and workshops on the application of an education model oriented to the development of competences and with a constructivist focus. In order to achieve this goal, the acquisition and development of teachers' knowledge and skills are implied.

As a result, the Faculty of Medicine at the Autonomous National University of Mexico (UNAM) created and implemented the elective course introduction to teaching in the biomedical area specifically structured to influence the development of these skills on teachers in training. However, it is necessary to have feedback on the contents to assess whether this course achieves its goal to have students acquire the procedural and behavioral curricular contents in order to contribute to a better training of future teachers and, in the end, favor the implementation of a competency oriented education model.

\section{Method}

This is an observational, descriptive and transversal study. The population studied were eleven 4th year medical students registered in the elective subject Introduction to teaching in the biomedical area.

A total of 11 2nd year medical students were enrolled in the pilot course offered from January to May 2017 with a length of 34 hours. In the sessions, the active participation of the members was promoted, as well as the divergence of opinions in regard to each of the topics. The activities applied during the course were: 1) the approach to concrete cases of real life situations or similar to institutional and education context in which they perform; and, 2) critical analysis and literature discussion. An education platform (Edmodo) was used to keep a close communication between teachers and students, as well as providing of didactic and additional material (literature, videos, lectures).

The assessment of the acquisition of procedural curricular contents (PCC) of students who took the subject was done by means of a pedagogical referents tool that was applied at the beginning and end of the course (Martínez et al., 2001) as well as an analytical rubric to assess a self-video of a class given by the participants. The pedagogical referents tool was comprised of 42 items, with a $\mathrm{Li}$ kert-type scale grouped in five strategies: 1$)$ Learning ( 7 items): inquires about beliefs the teacher has about the responsibility of learning and teaching. 2) Planning (4 items): refers to the organization of the activities involved in teaching. 3 ) Methodology (17 items): used by the teacher according to his personal belief on how to approach the academic program's contents; for example, considering the student's skills. 4) Assessment (5 items): explores the purpose for the teacher (achieve goals, feedback, among others); and, 5) Teacher-student relationship (9 items): inquires about the teacher's beliefs in regard to the relationship that must be held with students.

The analytical rubric assessed the didactic planning of a class at the beginning, during its implementation, and end. The topic was considered at free will but 
within the biomedical area, and the class addressed at least six students for a maximum time of 15 minutes.

For the assessment of behavioral curricular contents (BCC) the following self-application tools were developed. The first was a rubric on pedagogical leadership with two dimensions to explore (teacher qualities and skills as a pedagogical leader) and a graduated progressive score scale: 1) insufficient; 2) sufficient; 3) good; and, 4) excellent. The first dimension assessed self-perception on the human qualities of pedagogical leadership the participant demonstrated: inspiring, self-critical, colaborative, trainer of other human resources and moral authority. The second dimension assessed self-perception of teaching skills (e.g. pedagogical leader) the participants considered themselves to have: learning facilitator, being cognizant of different learning styles, acknowledges participation, offers academic/technical advice, and the ability to solve unforeseen situations. The second was a rubric on motivation in the teaching field with three dimensions to explore (affective, cognitive and volitional) and five progressive levels of domain with a score scale, with 1 as the lowest and 5 as the highest domain. The affective dimension assessed the drive to design learning activities, ability to gauge student interest, and ability to offer encouragement and support to overcome professional challenges. The cognitive dimension assessed the ability to master the topics, and the methodologies used to organize them to provide successful learning. Lastly, volitional dimension assessed the ability to manage a successful class without using "penalties or rewards", and the challenges and responsibilities the educators face when teaching.

Both rubrics were applied in two different stages, at the beginning and at the end of the subject. All rubrics were designed according to the criteria established by Malini and Andrade in 2010. For the analysis of data, the SPSS V21 software was used and a comparison of means was carried out for non-independent samples with a $\mathrm{T}$ test.

\section{Results}

\section{1) Assessment of Procedural Curricular Contents (PCC) Acquisition}

At the end of the course, there was significant variability among student with teaching strategies that are related to the "traditional methods" of teaching (Table 1). There was more homogeneity among students with teaching strategies in the "alternative" or "educational technology" referents both in the beginning and end of the course.

With regards to assessment of didactic planning, students showed a high performance in general (22 points out of 27). When assessing the students during the class, the high performance was in the "didactic sequence" category (100\%), followed by "an adequate use of time" (90.9\%). performance with average scores were "implementation of teaching strategies according to the topic's objectives" (72.7\%), "carrying out feedback with the learning (closing dimension)" (72.7\%) and "relating his/her teaching strategy with the development of competences considered in the academic program (development dimension)" (63.6\%). Lastly, 
Table 1. Percentage of students according to learning strategies in the different pedagogical.

\begin{tabular}{ccccccc}
\hline \multirow{2}{*}{ Referent } & \multicolumn{6}{c}{ Referents type } \\
\cline { 2 - 7 } & \multicolumn{7}{c}{ Traditional \% } & \multicolumn{2}{c}{ Alternative \% } & Educational Technology \% \\
\hline Strategy & Pre & Post & Pre & Post & Pre & Post \\
Learning & 80 & 73 & 100 & 91 & 82 & 91 \\
Planning & 27 & 9 & 100 & 95 & 100 & 100 \\
Methodology & 63 & 48 & 90 & 87 & 76 & 67 \\
Assessment & 36 & 27 & 77 & 73 & 91 & 86 \\
Teacher/Student Relationship & 100 & 73 & 86 & 80 & & 86 \\
Total & 61 & 46 & 91 & 85 & 87 & \\
\hline
\end{tabular}

Pre $=$ at the beginning of the course; Post $=$ at the end of the course.

the performances with the lowest score were "considered a diagnostic assessment (closing dimension)" (54.5\%) and "promotes teamwork (development dimension)" (45.4\%).

\section{2) Assessment of Behavioral Curricular Contents (BCC)}

The perception on the teaching qualities and skills of a pedagogical leader that participants owned before the course showed a minimum downward tendency. However, no statistically significant differences were found in any tool dimensions. This situation was also present when assessing the self-perception of intrinsic motivation in teaching (Table 2).

\section{Discussion}

The purpose of this study was to assess the elective subject, Introduction to teaching in medical students, which taught medical students interested in training as future educators during their formal medical training. This course emphasized teaching medical students principles of learning and acquiring core competencies.

It should be noted that the curricular assessment was internal and is linked to the academic achievement of declarative and procedural contents. Furthermore, the value of this study was in the assessment of learning, which was not done to criticize, but rather to assess the educational process that aims to motivate and provide direction to students interested in academic medicine, in addition to promoting self-regulation and leadership (Epstein, 2007).

The results of this study show that in the evaluation of learning with a training assessment, a shift towards the preference for alternative and educational technology referents was made at the end of the course (Table 1). The former preference is highly convenient for the programming of a study plan oriented to the development of competences, since the instructor is viewed as being a guide in the sense of designing learning situations and of scenarios for problem solving.

The aforementioned shows that the course influenced the change of pedagogical thinking, which, according to Pérez et al. (2007) suggests is critical in the 
Table 2. Perception of the dimensions on pedagogical leadership and motivation in teaching.

\begin{tabular}{ccccc}
\hline Tool & Dimensions & Pre $(\mathrm{x})$ & Post $(\mathrm{x})$ & $\mathrm{p}$-value \\
\hline \multirow{2}{*}{ Pedagogical leadership } & Qualitiess & 12.27 & 12.09 & 0.815 \\
& Teaching abilities & 13.72 & 13.45 & 0.823 \\
& Affective & 3.97 & 3.77 & 0.108 \\
\multirow{2}{*}{ Motivation in teaching } & Cognitive & 4 & 3.77 & 0.270 \\
& Volitional & 4 & 3.90 & 0.616 \\
\hline
\end{tabular}

training of educators. There autors state that promoting the reconstruction of the daily pedagogical thinking implies the need of a process of deconstruction of the schemes of thought that are non-critically and empirically consolidated.

The results of the pedagogical referents tool at the beginning of the course showed a greater agreement with the alternative and education technology referents. This may be due to the fact that the average age of students interested in teaching training was 22 . The differs with another study results, whose population were teachers of an older age who were more in agreement with the traditional referent (Urrutia et al., 2018).

In regards to didactic planning, the results showed that at the end of the course and once students had to plan a class, they applied the knowledge related to the sequence and administration of time, unlike the diagnostic and teamwork assessment, aspects that constitute an important area of opportunity. It is important to highlight the correlation with the pedagogical referents results, due to the fact that students were more in agreement in the planning with the alternative referent, they organized the activities around teaching. In methodology, however, students were in a greater agreement with the traditional referent, which leads to believe that they did not approach contents of the academic program taking into consideration the abilities of other students. Therefore, we can say that students behaved as a novice educator, one who has recently began teaching, and thus, they are still considered as inexperienced in this field. This starting stage is comprised of the first teaching years, in which educators must carry out the transition from students to teachers (Bozu, 2009). Hence, these students demonstrated the same insecurities of a new educator: how to correctly apply what they learned about pedagogy, the fear to control a class, becoming preoccupied with time constraints and focusing on successfully covering the course objectives rather than developing their own teaching skills (Vélaz de Medrano, 2009). In general, the novice educator has a knowledge base of the subject being taught, but has not yet received didactic training on how to teach it, due to various reasons, which include experience and age in our population studied. Furthermore, the literature shows that other didactic issues exist within inexperienced teachers, including application of methodology and implementation of course and self-assessment, which was also the case of our studied population (Villarroel \& Bruna 2017; Sánchez \& Mayor, 2006). Bozu (2010) and Vivas et al. 
(2005) emphasize the importance of beginner educators receiving guidance from more experienced teachers, aspects that complement each other in our course with activities that link their learning with teaching situations within the current educational context.

On the other hand, pedagogical leadership implies a polysemic term, and in literature different conceptualizations are perceived (Macneill et al., 2005; Male \& Palaiologou, 2012; Medina \& Gómez, 2014). The focus used in this study places the pedagogical leader with "transforming" functions of his educational environment to improve the quality of the teaching practice, and with an end result of learning (Bolívar, 2010). During the course sessions, students perceived to have high scores in regard to qualities and skills of pedagogical leadership. However, they also reflected about its complexity and the need to develop a wide breadth of teaching competences that are eventually acquired with experience. The latter could explain why the scores obtained during the second assessment are a little bit lower; as the population studied do not have the expertise to consciously be aware of the teaching-learning process of a group of students. As such, throughout the course emphasis was placed the importance of training educators as pedagogical leaders to face these challenges. Young (2016) carried out a qualitative study, which identified that pedagogical leadership necessary for the development of the novice teacher and in order to become more effective as an academic. Hence, the educator in training must develop his professional competences of leadership, and in addition, learning through self-reflection, assessment from students and feedback from peers (Male \& Palaiologou, 2012).

At the same time, teachers enrich their academic career daily by facing dilemmas, disagreements, challenges, problems or conflicts with students or peers in the field. These situations are intellectual stimuli, motivation and an incentive to promote learning in the practice of teaching and personal growth (Sleegers, 1999). If presented with one these situations while teaching, the educator will determine the way to solve it by analyzing it, reconstructing his or her own thought process and modifying their teaching strategy to assign a new meaning to the situation (González, 2003). Although the course was for to students interested in getting trained as future educators, it may be that in the case of motivation, self-reflection on development and performance as instructors is challenging, as they are inexperienced in the ability to make changes on the spot when lecturing a group.

\section{Conclusion}

Assessment of the course offered to medical students interested in academic medicine demonstrated that students had a preference for alternative and educational technology referents at the end of the course. The former preference is ideal for the creation of a study plan oriented toward the development of competencies-based courses. Innovations in education delivery have demonstrated that in addition to mastering the subject, lecturers must be able to deliver information and incorporate teaching strategies that promote successful learning by 
students. In order to provide current educators with these strategies, it is important to promote the development of professional competencies and tools for self-assessment during training to become educators. Future research should incorporate the observations made in this study in order to assess whether preference of these referents results in their implementation and eventual successful learning by future students.

\section{Acknowledgements}

The authors thank Josefina Bolado for editing and translation of this text into the English language.

\section{Financing}

Programa de Apoyo a Proyectos para la Innovación y Mejoramiento de la Enseñanza, Universidad Nacional Autónoma de México, número PE 400417.

\section{Competing Interests}

The authors declare that they have no competing interests.

\section{References}

Bhutta, Z. A., Chen, L., Cohen, J., Crisp, N., Evans, T., \& Fineberg, H. (2010). Education of Health Professionals for the 21st Century: A Global Independent Commission. The Lancet, 375, 1137-1138. https://doi.org/10.1016/S0140-6736(10)60450-3

Bolívar, B. A. (2010). How Does a Pedagogical and Distributed Leadership Improve Academic Achievement? Magis. International Journal of Research in Education, 3, 79-106.

Bozu, Z. (2009). The New University Teaching Staff and Their Professional Induction Process. Magis. International Journal of Research in Education, 2, 317-328.

Bozu, Z. (2010). Young University Professors in the Current Context of University Education. Keys and Controversies. Iberoamerican Journal of Education, 51, 1-15.

Epstein, R. (2007). Assessment in Medical Education. The New England Journal of Medicine, 356,387-396. https://doi.org/10.1056/NEJMra054784

Esquivias, S., \& González, C. A. (2005). The Teacher as a Student: Thinking, Attitudes and Academic Performance. Interuniversity Electronic Journal of Teacher Training, 8 , 23-32.

González, T. M. (2003). Keys to Encourage Teachers' Motivation in the Face of Current Educational Challenges. Estudios Sobre Educación, 5, 61-83.

Macneill, N., Cavanagh, R. F., \& Silcox, S. (2005). Pedagogic Leadership: Refocusing on Learning and Teaching. International Electronic Journal for Leadership in Learning, 9.

Male, T., \& Palaiologou, I. (2012). Learning-Centred Leadership or Pedagogical Leadership? An Alternative Approach to Leadership in Education Contexts. International Journal of Leadership in Education, 15, 107-118. https://doi.org/10.1080/13603124.2011.617839

Malini, R. Y., \& Andrade, H. (2010). A Review of Rubric Use in Higher Education. Assessment \& Evaluation in Higher Education, 35, 435-448. https://doi.org/10.1080/02602930902862859

Martínez, G. A., Ferrés, G. A., \& Gutiérrez, D. S. (2001). Referentes pedagógicos y estra- 
tegias de enseñanza delos profesores de la Maestría en Ciencia Bioquímicas de la UNAM. Revista Anuies, 4, 54-59.

Medina, R. A., \& Gómez, D. R. M. (2014). Pedagogical Leadership: Skills Needed to Develop an Improvement Program in a Secondary School. Educational Perspective Teacher Training, 53, 91-113.

Pedroza, A. V., \& Infante, T. D. (2010). A Perspective on the Attitudes and Duties of the Teachers in the School Classroom. Journal of Education and Development, 14, 53-58.

Pérez, G. A. I., Martínez, M., Amelia, T., Essombra, M. A., \& González, G. M. T. (2007). Faculty and Other Education Professionals. Spain: Octahedron.

Rodríguez, M. G. (2011). Functions and Features of Pedagogical Leadership in Teaching Centers. Education and Educators, 14, 253-267. https://doi.org/10.5294/edu.2011.14.2.1

Sánchez, M. M., \& Mayor, R. C. (2006). The Young University Professors and Their Pedagogical Training. Keys and Controversies. Journal of Education, 339, 923-946.

Sanjurjo, H., \& Placci, A. (2011). The Construction of Teacher Professional Knowledge in the First Processes of Socialization: The Insertion in the Educational Institutions of the City of Rosario of the Teaching Graduates of the Careers of Letters, History and Education Sciences. In VI National Conference on Teacher Training. Curriculum, Research and Practices in Contexts. Mar del Plata.

Sleegers, P. (1999). Professional Identity, School Reform, and Burnout. In R. Vanderberghe, \& A. M. Hubermand (Eds.), Understanding and Preventing Teacher Burnout. A Sourcebook of International Research and Practice (pp. 247-255). New York, NY: Cambridge University Press.

Torres, A., Ruiz, J., \& Álvarez, N. (2007). The Self-Transformation of the University Student: Beyond the Integral Formation. Iberoamerican Journal of Education, 43, 1-9.

Urrutia A. M. E., Fuentes, G. R. S., García, V. H., Beck, E., Aburto, A. M. B., \& Guevara, G. R. (2018). Impact of Teaching Strategies on Medical Student Academic Performance. Global Journal of Health Science, 10, 19-27.

https://doi.org/10.5539/gjhs.v10n2p19

Vélaz de Medrano, C. (2009). Competences of the Teacher-Mentor for the Accompaniment of the Beginning Teacher. Curriculum and Teacher Training Magazine, 13, 210-229.

Villarroel, A. V., \& Bruna, V. D. (2017). Pedagogical Competences That Characterize a University Teacher of Excellence: A Case Study That Incorporates the Perspective of Teachers and Students. University Education, 10, 75-96.

https://doi.org/10.4067/S0718-50062017000400008

Vivas, C. M., Becerra, T. G., \& Díaz, H. D. (2005). The Formation of the New Teacher in the Department of Pedagogy of the University of Los Andes Táchira. Revista Electrónica de Investigación Educativa, 7. http://redie.uabc.mx/vol7no1/contenido-vivas.html

Young, Y. L. (2016). Pedagogical Leadership to Support New Teachers' Growth. Master's Thesis in Education, University of Jyväskylä, Department of Education. 